This item was submitted to Loughborough's Research Repository by the author.

Items in Figshare are protected by copyright, with all rights reserved, unless otherwise indicated.

\title{
A qualitative investigation of foundation year 2 doctors' views on the European Working Time Directive
}

PLEASE CITE THE PUBLISHED VERSION

http://dx.doi.org/10.1108/JHOM-08-2013-0172

\section{PUBLISHER}

(C) Emerald Group Publishing Ltd

\section{VERSION}

AM (Accepted Manuscript)

\section{PUBLISHER STATEMENT}

This work is made available according to the conditions of the Creative Commons Attribution-NonCommercialNoDerivatives 4.0 International (CC BY-NC-ND 4.0) licence. Full details of this licence are available at: https://creativecommons.org/licenses/by-nc-nd/4.0/

\section{LICENCE}

CC BY-NC-ND 4.0

\section{REPOSITORY RECORD}

Duncan, Myanna, and Cheryl Haslam. 2019. "A Qualitative Investigation of Foundation Year 2 Doctors' Views on the European Working Time Directive". figshare. https://hdl.handle.net/2134/19393. 


\section{Introduction}

The European Working Time Directive (EWTD) came into force for consultants and other grade careers doctors in October 1998 as part of the Working Time Regulations (Office of Public Sector Information, 2008). However, it was not until August 2004 that the Directive was applied to doctors-in-training. The EWTD is part of health and safety legislation, largely designed to prevent excessive working hours and improve the conditions of hospital based medical doctors (Bamford \& Bamford, 2008). Specifically, the EWTD has imposed a staged reduction in junior doctors' average working hours from 58 hours in August 2004; an interim 56 hours in August 2006; to 48 hours in August 2009. The Directive also stipulates a number of minimum rest requirements based on the SiMAP (2000) and Jaeger (2002) judgements in the European Court of Justice. These requirements include a minimum of 11-hours continuous rest in every 24-hour period. Given that health care provision is a 24 hour service, the Directive has had a major impact on the practice of UK based medicine.

\section{UK Implementation of the EWTD}

Individual employers are responsible for ensuring doctors-in-training are compliant with Directive requirements and monitoring exercises are conducted at National Health Service (NHS) Trust level at least biannually. Monitoring exercises are conducted for a minimum of two weeks during which time data is collected from all grades of doctors and other nontraining grade medical staff. A minimum return rate for monitoring exercises is $75 \%$ of doctors participating in the monitoring return rate, and $75 \%$ of all monitored duty periods to be documented. Locum doctors-in-training are included as are trainees in flexible training posts. Monitoring systems record a range of information including contracted duty hours; 
actual hours of work; total and continuous rest periods; gaps between shifts; natural breaks; and leave and cover arrangements (British Medical Association, 2004). Where compliance problems are identified, or where a minimum return rate has not been achieved, further monitoring exercises are conducted. In addition, hours monitoring must be conducted when new rotas have been introduced. In these circumstances, the monitoring exercise must occur within six weeks of the introduction of the new rota (Department of Health, 2002).

Whilst individual Trusts are responsible for compliance, the Health and Safety Executive (HSE) is responsible body for the enforcement of the Directive in the UK. The HSE closely regulates: the maximum weekly working time limit; night work limits; and health assessments for night work. Penalties for non-compliance include possible employment tribunal proceedings by employees, orders for compliance (from the Health and Safety Executive) and fines of up to $£ 5,000$ per doctor per day for non-compliance. In addition, the Department of Health may also be at risk of enforcement proceedings by the European Commission.

In order to address the requirements of the European Working Time Directive, there has been major reform to the practise of UK based medicine. A number of specific initiatives have been introduced as a response to the Directive which include: the move to shift-based working practices; the reallocation of work including the creation of new job roles for healthcare assistants; increased collaboration between specialties including increased use of cross specialty cover; and increased staffing numbers.

One specific multi-professional working initiative which has been introduced is entitled the 'Hospital at Night' scheme. This has redefined the traditional model of out-of-hours clinical cover in a hospital based environment (McDonald \& Eccles, 2004). The Hospital at Night model initiated a move from the provision of cover by means of professional delineation or 
staff grade, towards a multi-disciplinary team based approach, defined by competence. Multiprofessional working initiatives, such as Hospital at Night, appear to address restrictions on working hours through a number of mechanisms. First, it has been suggested that reallocating non-essential jobs to other members of the healthcare team reduces work pressures on doctors (Wilkinson, 2008). Second, this may also enhance the roles of other professional groups who are looking to acquire new skills meaning, they are suitably skilled to provide staff cover when necessary.

In line with the reallocation of tasks as a response to the reduction in available hours for junior doctors, a number of new working roles have been created for healthcare workers. Specific roles include those of Nurse Practitioners and Specialist Nurses who increasingly perform tasks which were traditionally allocated to junior doctors. For example, there has been support for the use of these staffing groups to carry out cannulation, phlebotomy and some vascular procedures (Department of Health, 2004). However, research from the nursing literature has highlighted the resistance of doctors, particularly junior doctors, to the changes in these working roles and practises (Wilkinson, 2008). This has been attributed to the upskilling of senior nurses and the blurring of boundaries between junior doctors and nurses, and has been cited as one of the barriers to effective multi-disciplinary working initiatives.

\section{EWTD \& the junior doctor}

Concerns with reductions of junior doctors' hours have been reported in the literature (Moonesinghe et al, 2011), including the impact on continuity of care (Lowenstein, 2003) and reduction of training opportunities (Cass et al, 2003; Fernandez \& Williams, 2009). Furthermore, research has identified specific concerns regarding the impact of the EWTD on 
junior doctors’ opportunities for clinical experience, training, continuity of care and job satisfaction (Mather \& Pounder, 2005; Shah et al, 2004). A survey by the Royal College of Surgeons has indicated that the observed changes to working hours have had major negative effects on the working life, free time, and education of junior doctors (Lowry \& Cripps, 2005). Additionally, evidence also indicates that under the EWTD junior doctors have to spend an increasing proportion of their working time 'handing over' work to incoming staff which has reduced time available to provide direct patient care (Cairns et al, 2008), increased administrative duties and had an adverse impact on training. Given the demands EWTD 2009 has presented, the literature has indicated the importance of maximising time spent at work, particularly in terms of training.

Whilst the literature has highlighted the advantages of multi-professional working initiatives (Department of Health, 2005), research has pointed to junior doctors resistance to the changes in these working roles and practises. Research by Wilkinson (2008) involved semistructured interviews with a range of healthcare professionals, including doctors (training grade not specified), nurses and healthcare managers. The findings from the study highlighted some ambivalence towards reforms in working practices owing to the major shift in culture for the medical profession per se. The research detailed some interesting findings regarding a perceived blurring of role boundaries particularly between junior doctors and nurses, resulting from the up-skilling of nurses. Findings indicated this had, in some instances, resulted in friction between the different working groups, with the study pointing towards ‘some resentment on a personal level’ (Wilkinson, 2008, p. 207). The study suggested that the reported tension may be attributed to issues such as demonstrating authority and changes in levels of autonomy. Therefore, this study highlighted some important aspects relating to 
core components of job characteristics including skill variety, task identity, task significance and autonomy.

The literature has also noted an interesting phenomenon among junior doctors since the implementation of the EWTD, describing a wider cultural move towards a shift mentality. Doctors have therefore been described as focused on 'clocking on and clocking off' (Bamford \& Bamford, 2008). Indeed, Ahmed-Little and Bluck (2006) have commented that:

'...some argue EWTD is creating a generation of clock-watchers and gradually eroding away good will amongst juniors and seniors alike’ (Ahmed-Little \& Bluck, 2006, p. 373)

In line with the introduction of shift-based working, studies have highlighted concerns regarding continuity of care, insofar as junior doctors being involved in the whole patient journey from the admission stage through to diagnosis, management, discharge and finally follow up (Mather \& Pounder, 2005). There have therefore been concerns reported in the literature regarding the impact of the Directive on training opportunities and general morale in the workforce.

Furthermore, evidence has suggested that the move to a shift based model has served to increase Consultant workload and commitments. Despite Consultants being covered by the terms of the Directive, commentaries suggest that their ability to opt-out and increased autonomy has meant they are working harder than ever, with some arguing that senior medics may be pressurised to take on extra hours, particularly during the out-of-hours period (namely nights and weekends) to support the drop in hours of junior trainees (Richards, 
2009). Consequently, there have been concerns this may decrease Consultant availability in day time periods and, as such, adversely impact junior trainees (Chesser et al, 2002).

\section{Research aims}

Despite the manifold editorials, commentaries, and opinions which have been expressed regarding the EWTD, analysis of published literature indicates a lack of research examining junior doctors' perceptions of the impact in the reduction of hours, particularly out-of-hours exposure resulting from the EWTD. Specifically, there appears to be a lack of qualitative research in this area. Because active teaching typically occurs during the weekday day-time periods, out-of-hours shifts potentially offer little extra training value. However, without empirical evidence it is difficult to validate these claims. The present research sought to address the gaps in the literature by exploring the personal views and experiences of Foundation Year doctors operating under EWTD rotas. The study was conducted with the support and ethical approval of a collaborative UK Postgraduate Deanery.

\section{Methods}

\section{Participant recruitment}

Following Research \& Development ethical approval for the study from the East Midlands Healthcare Workforce Deanery, an invitation to participate in the study was distributed to all Foundation Year 2 junior doctors working in the Deanery at the time (396 doctors) via the Deanery's internal communication system. The invitation was distributed in September 2007, 
meaning the cohort of doctors selected had been working for 1 year post basic medical qualification across a range of medical, surgical and other posts. Doctors were not necessarily affiliated with the collaborating Deanery for their first year of training. The research invitation provided an overview of the study and requested participation in a one-to-one semistructured interview. Interviews were arranged at a mutually convenient date and location. Owing to time and financial constraints, the study employed a convenience sampling technique. No incentive was offered for participation in the research.

\section{Participant characteristics}

Twenty-one women and 15 men responded to the research invitation and proceeded to participate in the study. Participants' ages ranged from 23 to 34 years (median 24 years). Four of the participants had completed their previous training year in a Deanery different from that in which they were presently working. Thirty-six interviews, a 9 percent response rate, was deemed sufficient, as by the final interview no new information emerged and data saturation had been reached. All interviews were conducted by the same researcher to ensure consistency. Nineteen interviews were conducted in person and 17 interviews were conducted via the telephone. The interview duration ranged from 22 to 57 minutes, lasting on average 39 minutes.

\section{Interview procedure}

For the purpose of the research, the semistructured interview method was selected to allow for a rich and in depth exploration of issues. An interview schedule was devised in consultation with the literature, from discussions with key stakeholders and pilot interviews 
with junior doctors. Prior to completing the interview, participants were provided with introductory paperwork and also provided their consent to participate in the study. Typically this occurred one week prior to conducting the interview.

The interview schedule covered socio-demographic and background information about doctors' previous and current working schedules, followed by a combination of structured and open ended questions pertaining to the research objectives. Interview questions were organised into five sections: background; workplace stressors; EWTD; the night shift; and sleeping habits. An example question from the background section includes 'Can you tell me about your current working arrangements with regards to hours worked?’. An example question from EWTD section includes 'How do you think the introduction of the EWTD has impacted on your well-being?’.

The nature of the semistructured interview method allowed participants to discuss issues which were not specifically incorporated into the schedule and facilitated a flexible exploration of emergent topics. Prior to commencing the interview, participants were given an overview of the study and verbal consent was obtained to audio record the interview. If consent was not given, which occurred in only one interview, participants provided their consent for written notes to be made.

\section{Data analysis}

The recorded interviews were transcribed verbatim and imported into the qualitative software tool NVivo (Version 7.0). Template analysis was used to analyse the interview transcripts. This analytic technique provides a structured yet highly flexible approach which is well 
suited to research that wishes to provide a pragmatic worldview approach (King, 1998). The analysis of the data followed a 5 stage process. First, prior to conducting the interviews, the principal researcher developed a coding template designed to represent important themes as based on theoretical assumptions and expectations. Second, once the interviews had been conducted, the researcher scrutinized each script in detail and applied codes from the original coding template where appropriate. Third, the coding template was revised, modified and extended in light of emergent data. Once all transcripts had been coded by the principal researcher, a random 10 percent sample of the coded data was validated by an independent researcher trained in qualitative analytic techniques. At this stage, any inconsistencies in coding between the researchers were discussed until consensus was achieved. Finally, the coded data formed the foundations for verification and conclusion drawing as can be observed in the following section.

\section{Results}

The following section broadly examines participants' views regarding the EWTD, before exploring the ways in which the Directive has impacted working schedules. Finally, the section assesses the perceived utility of different working schedules, examines quality of working life and psychosocial working conditions.

\section{Importance of regulated working hours}

The overwhelming majority of participants largely recognised the need for a regulation of working hours in the medical profession and understood why the Directive had come into 
force. Participants frequently discussed the dangers of a return to the 'old days' whereby 110 hour working weeks were typical and the detrimental consequences of such working practices.

\section{Box 1: EWTD as a welcome initiative}

I think I'm in favour of a time directive. I think the past has shown that doctors were working ridiculously long hours and it was affecting them and the care and safety of their patients. (Pp. 29, Man, Age 25)

I am personally in favour of it (EWTD) having worked in hospitals and knowing the value of on-calls but knowing you need to get the balance between being able to work safely and work happily and being able to work happily is quite important to me. (Pp. 17, Woman, Age 34) I also think an extremely tired doctor isn’t particularly going to learn effectively so learning-wise if you're working more reasonable hours then you're more alert and you're more capable of learning and progressing at work. (Pp. 7, Man, Age 24)

Several of the participants acknowledged the positive impact the Directive had on their general health and wellbeing, work-life balance, and opportunities for personal and professional development. Furthermore, doctors typically recognised that regulation has been instrumental in creating a shift in the medical mentality whereby doctors are encouraged to take better personal care and not just work until they reach burnout. Moreover, a number of doctors recognised that improved self-care benefits doctors in terms of their effectiveness within the workplace. 


\section{Frustration at excessive regulation}

While acknowledging the benefits of regulation, a large proportion of the participants felt that 'the pendulum has swung too far' with regards to the restriction on hours, and reported frustration at the limits imposed by EWTD. Nearly all doctors interviewed regarded the 48 hour upper working limit as too stringent, expressing personal concerns and also apprehension for the medical profession as a whole.

\section{Box 2: Working hours too stringent}

I can understand that they want to limit hours but I think they're setting the limit too low. I think a 60 hour week limit would be reasonable. I don't really think any of us went into medicine expecting to work a 48 hour week and that's not why we went into medicine, we did that because we want to work the hours to get the experience. (Pp. 19, Woman, Age 27)

Participants further mentioned that the nature of medicine invariably means that a shift can overrun because emergencies arise and patients cannot be left if they are ill. Doctors also commented that often it takes longer to fully handover a job to the next doctor on shift than it would do complete the job oneself. Accordingly, the majority of doctors reported staying beyond their shift as a regular occurrence. Whilst doctors did not appear to begrudge this, accepting it as their medical duty, several commented that without the willingness of staff to do this, the NHS system would collapse. In this vein, a number of participants regarding the 'clocking off mentality' of upcoming trainees who do not share the value of previous cohorts and the increased strain this will place on the system. 
With regards to short-term personal apprehensions regarding the 48 hour working week, a number of doctors discussed issues relating to insufficient exposure and an associated lack of confidence.

\section{Box 3: Exposure and confidence}

Bear in mind we only get to do 3 out of 6 (rotations) for the whole foundation programme and that 3 of mine were very restricted I do feel that I perhaps may have had certain doors closed. For example, if I was applying for a specialty post and was up against a candidate who had had greater experiences within that speciality I personally would feel disadvantaged. (Pp. 1, Male, Age 23)

I was worried that I wouldn't be able to see enough and manage enough on my own to feel confident doing it later on, because I know this year and next year they're going to be looking at me saying you do this, you manage it, you are the more senior person here, and I just think that's a bit unfair because you've not let me build up the skills and the experience to get to that position.

(Pp. 5. Woman, Age 24)

Participants expressed anxieties at reaching a more senior level and being expected to complete a certain job or procedure yet having inadequate preparation and experience of this. This served to highlight that Directive necessitates a shift in expectations from both senior and junior colleagues. Several doctors also mentioned their restricted experiences, resulting from fewer hours, had impacted their immediate choice of career specialty. 


\section{Impact of EWTD on rota design}

Participants reported frustration at the way in which the Directive had been implemented with regards to rota design. In particular, junior doctors reported concerns at cutting hours to meet EWTD requirements by removing out-of-hours working. Issues were also raised with regards to the fragmentation within the current cohort of Foundation doctors because of the lack of national standardisation regarding rota design.

\section{Box 4: Fragmentation of experience}

They're taking out on-calls which means you're going to get to a more senior level and do on-calls for the first time and be expected to be at the level people are at the moment when they get there having done years and years of on-calls. So I just think its gonna struggle. (Pp. 4, Man, Age 24)

I had 8 months of Monday to Friday 9 to 5, and other people had all their jobs banded so all of them were busy. There's just such variation and at the end of your house year. Some people will just happily run the ward on their own whilst some people, like myself, felt so unconfident at dealing with any sick patient because you had no experience of it and it just means there is such discrepancy between different house officers at the end of the year. (Pp. 19, Woman, Age 27) I will probably not trust them (new doctors) as much and may therefore take more of the workload and responsibility upon myself. (Pp. 14, Man, Age 30)

The reported discrepancy in shift experiences equated to perceived unfairness among junior colleagues. In relation to this, concerns were raised about securing more senior Specialist Training posts having had limited experiences. A number of issues discussed regarding working with less experienced colleagues and issues rose in terms of unease at the standard of the new and upcoming doctors and associated burden on seniors. 


\section{Working arrangements}

Each participant had experienced a unique working arrangement as a Foundation trainee. However, at the time of data collection, all had, at some point, encountered day shifts, day on-call shifts, weekend on-call shifts and night shifts, albeit in different hospitals and specialties. This meant that doctors were able to discuss the opportunities afforded by different working arrangements. The overarching theme was 'out-of-hours' working, referring to evenings, weekends and night shifts. All participants, bar one, were averse to the removal of out-of-hours working for foundation doctors, both current and future trainees. Approximately half of participants discussed the reasons for this in relation to personal experiences of having out-of-hours shifts reduced or removed.

\section{Box 5: Out-of-hours working}

I think that (out-of-hours) is when you learn the most really. It's not formal teaching that you get at those times (out-of-hours) but there's more opportunities to get hands on skills experiences because there aren't as many people wanting to do things. Also there are not so many other people around to call for help you get more out of it because you actually have to put what you've learnt in to practice. (Pp. 3, Woman, Age 24)

No matter how many other opportunities you're given to gain experience, the real time when you learn and when you have to stand on your own two feet is when you're on your own, in an 'out-ofhours' situation with a sick patient. Certainly looking at my learning over the last 2 years, there have been the times when I've learnt the most and that I draw on when I'm doing reflective practice...you know, really taught me vital lessons about being a doctor. (Pp. 32, Man, Age 25) 
Increased experience, resulting from less competition from colleagues, was frequently reported as an advantage of the out-of-hours shift. Participants noted that out-of-hours working offered increased opportunities for clinical decision-making under pressurised circumstances in an autonomous supervisory environment. The unique nature of out-of-hours working appears to provide specific learning opportunities as doctors draw on timemanagement and prioritisation skills. Participants reported frustration at day-shifts because of a lack of autonomy and limited opportunities to engage in medical decision-making. The vast majority of participants associated day-shifts with administrative duties. Accordingly, dayshifts were typically perceived as service provision, meaning even greater value was placed on out-of-hours.

\section{Box 6: Day shifts compared to out-of-hours}

Because it's the time when there are less staff around and so you get to do more or you're the first one to see the sick patient and you do have to make more decisions on your own with just a phone call for help. So you just get more out of that because you have to think more about things rather than just turning to somebody else straight away and saying what do I do? (Pp. 11, Man, Age 26)

I find personally that during the normal working day, really your duties are more secretarial and logistical. When it's an out of hours part of your day, that really is when you're actually doing, you're actually using your training and knowledge that you've gained to assess patients and make decisions about what happens and I think that you know that's the more difficult side of it.

(Pp. 34, Man, Age 24)

\section{Quality of working life}


Participants made reference to a broader cultural shift the Directive had introduced into medicine, insofar as doctors taking better personal care. Doctors also discussed the way in which the EWTD had been instrumental in heightening awareness of the deleterious effects of former years and reducing stigma regarding discussing this in the profession. However, whilst participants generally recognised that the Directive has been beneficial, a large number of interviewees emphasised that the way in which rotas were designed had, in some cases, not been propitious to juniors’ quality of working life.

\section{Box 7: Work-life balance}

So you'd still do 12 hours a day but, they (the Trust) say you get a couple of hours off in the morning when you can't take them. Or after you've done a week of nights or something they give you the next two days off which means that they comply but it is still not very social so you're still missing weekends and things like that. They've tried to be quite sneaky about it and that's what a lot of people don’t like.(Pp. 29, Man, 25)

If you do a week of nights you're doing 12 maybe more hours for seven days, that still adds up to over 90 hours, or if you work 11 days straight because you do a weekend on call up to 11 in the evening or $13 \frac{1}{2}$ hours which some of the weekends I did last year, it's still adding up to 90 or so. Yes, they might give you the days off in lieu but in terms of the main aim of the Working Time Directive which is to reduce the number of hours done in any one stretch, and make people less tired, it doesn't really achieve that, it seems to be quite a creative reworking of the rota. (Pp. 29, Man, 25)

They (the hospital) have this bizarre rota system which is disruptive to both our working and social lives. In order to make us compliant we have to come in one day a week and just do half day. So this could be in the morning say 8-12 or could be in the evening so we do 5-10. Its very frustrating and its all about meeting the 'requirements'. (Pp. 4, Man, 24) 
Participants voiced concerns that whilst on paper hours typically appear balanced, at ground level a working week may still be representative of the hours worked by senior colleagues prior to the implementation of the Directive. A number of participants alluded to the reference period over which average working hours are calculated as a means of manipulating numbers and doctors associated distrust with this. This theme implies that whilst Directive has gone some way in addressing excessive working in the profession, doctors are still dubious as to whether it had facilitated improvements in quality of working life. Participants also cited increased social isolation resulting from shift based working practices and the disruption to team based working resulting from ETWD rotas.

\section{Psychosocial working conditions}

The flexibility afforded by the semistructured interview method enabled participants to discuss in very broad terms their psychosocial working environment. When describing their job role, participants explored the nature of the responsibilities, their working hours, and general features of their working environment. Each participant was asked about the source and nature of work-related stressors which yielded a wide range of responses. A number of main themes repeatedly emerged during the course of data collection. One of the most common themes participants alluded to concerned their reported workload volume. Participants frequently discussed excess expectations and being unable to complete all designated tasks within assigned working hours.

Box 8: Unrealistic expectations 
It's just when you've got so much to do that you physically can't do it all and you're expected to be in about 3 places at once. So if you're the only one on and you've got a couple of sick people that's really stressful because you don’t know who to see first and sort them out.(Pp. 16, Female, 24)

Participants typically reported prioritisation skills as fundamental to their job role and the means by which they managed excess pressures. However, participants often reported a general reluctance to handover residual jobs due to an implicit understanding of excess pressure on staff largely embedded in the medical culture. Accordingly, the demanding workload was often discussed in relation to breeching hours as participants would stay at work until their had completed their jobs. A large number of participants specifically commented on excess workload pressures characteristic of the out-of-hours working period. In particular, interviewees associated these pressures with under staffing and general lack of support.

\section{Box 9: Workload pressures}

It's on calls where it's just because you're understaffed and you're running around like a lunatic trying to review all these patients and do all these jobs and see all the new admissions and you don't have time for a break and you're doing one thing and you've got other nurses kind of needing you to review sick patients or do things so that patients go home and you're trying to do five things at once, which becomes quite stressful and you don't ever get a break. (Pp. 3, Female, 24)

The data suggested that whilst participants valued the opportunities afforded by out-of-hours working that sheer workload was, during these times, excessive. Consequently, whilst the majority of participants viewed stress as adaptive in their working lives, most of these interviewees discussed their personal experiences of out-of-hours working as 
disproportionately and unnecessarily stressful. This stress was largely attributed to understaffing and general lack of support.

\section{Discussion}

\section{Principal findings}

This study provided an insight into views of Foundation Year 2 doctors' working under the European Working Time Directive. The research highlights that doctors typically welcome a regulation of working hours, recognising the benefits for their wellbeing and quality of working life, but observes participants concerns regarding the impact of the Directive on training opportunities. The data also underlines doctors' frustration at the manner in which the EWTD had been implemented, particularly with regards to removing of out-of-hours shifts as a means to meet Directive requirements, and the removal of worker control and autonomy. As such, the views of the junior doctors' interviewed suggest that the Directive has not necessarily benefitted those it principally claimed to assist. In so doing, the research further substantiates the survey by the British Medical Association (2008) which indicated some 57 percent of junior doctors thought doctors should be able to opt out of the 48 hour week.

The research has identified the perceived utility of the out-of-hours working period and, in particular, explained what out-of-hours offers over and above day-shifts. Whilst the junior doctor Foundation Programme has served to introduce structured training methods, and commentators therefore claimed that training takes place mostly during the day (Black, 2006), it seems that experiential training opportunities do continue to arise out-of-hours, 
largely due to decreased staff numbers and competition. By contrast, day-shifts remain well staffed, meaning opportunities for hands-on skills experiences are reduced and consequently the work of the junior doctor is often perceived as administrative in nature. However, the study served to highlight the excess workload pressures junior doctors' encounter during the out-of-hours period, which was attributed to understaffing and lack of support. As such, the data suggests a balance need be achieved between these working periods. One way in which to do this may be through increased help from nurses and support staff in performing routine tasks. An additional strategy may be through the inclusion of junior doctors in the design of rotas and through providing doctors with greater control in work design, which is supported by the job characteristics literature (Humphrey, Nahrgang \& Morgeson, (2007). The rationale behind the involvement of junior doctors in rota planning is evident. First, doctors work at front line and understand the medical culture, the different demands and requirements of the various medical specialties. Second, junior doctors recognise the challenges a reduction of working hours will introduce to training and service provision.

Through junior doctors taking ownership of their working practices and being actively engaged with rota design issues this may increase their perceived autonomy and therefore buy-in of working practices. In this vein, research indicates that junior doctors are instrumental and effective in leading both their peers and senior colleagues through periods of change (Kendall et al., 2009), of which the EWTD has brought about. Furthermore, the work design literature has suggested that:

'...employee-initiated changes in the design of jobs result in more complex, challenging and meaningful work - which, as now is well-established, is likely to foster positive work and personal outcomes.' (Oldman \& Hackman, 2010, p. 471) 
This therefore suggests that the involvement of junior doctors is key not only for engaging both themselves and their colleagues in new working practices, but also for providing juniors with greater meaning and enjoyment in their work (see Duncan, 2011).

\section{Strengths and weaknesses}

The present research is original by means of its use of qualitative research techniques to provide in-depth, empirical evidence of a broad range of junior doctors' views, not just those from the craft and surgical specialities, which has been the focus of previous studies (Lowry \& Cripps, 2005; Mather \& Pounder, 2005; Shah et al, 2004). The research had the additional benefit of being conducted by an independent research team not affiliated with the NHS. Consequently, participants might have been more open and forthcoming with their answers, safe in the knowledge that their answers would not be personally identifiable.

Limitations of the study include a relatively small sample of self-selecting participants, all of whom were in Foundation Year 2 of training in a single Deanery and had limited first-hand experience of working lives as qualified doctors. Although we acknowledge this shortcoming, the data does appear to reflect a range of working experiences and views, but we that do not claim that the results are generalisable to all junior doctors. Indeed, we recognise that had views been sought from different grades of doctor, particularly more senior doctors, then findings may have differed. We note that more senior doctors, particularly those working in the craft specialties, typically place great value on day time theatre sessions, day time clinics and interventional lists and often view out-of-hours as service provision. Consequently, we do not claim that the findings are generalisable across all specialties. 
An additional limitation of the research is that the juniors doctors interviewed only had experience of working within confines of EWTD, meaning their answers therefore only reflect what is personally known and they have no comparison bench mark. Whilst in one sense this acts as a limitation, responses served to provide a detailed insight into doctors' perceptions and that which they which they believe to be the case. Accordingly, the authors suggest this to be an advantage of the research. Finally, logistic constraints introduced some inconsistency regarding the medium of interview, which may be highlighted as a limitation. However, whilst previous literature has suggested that the different interview modes might yield different results, reviews have concluded no significant differences (Sturges \& Hanrahan, 2004).

\section{Conclusion}

The European Working Time Directive presents many challenges for the medical profession as NHS Trusts and UK Postgraduate Deaneries endeavour to comply with its requirements. We would encourage the use of the research findings to inform future rota design and workforce reconfiguration. Specific recommendations from this study are threefold. First, we would encourage day-shift work through better management of administrative duties to provide a greater emphasis on hands-on skills experience in a supportive, supervised environment so as to consolidate doctors' theoretical knowledge. This could be done through the increased use of clinical assistants, for example. Second, where possible, junior doctors might benefit from the opportunity to engage in out-of-hours working. Such opportunities might arise with multi-professional 'Hospital at Night' teams. Although we would endorse 
the opportunity for junior doctors' to engage in out-of-hours working, we recognise that this might not be possible. Accordingly, given the limits of junior doctors training under a 48 hour working week, it is imperative that doctors are given the opportunity to engage in clinical decision-making in an autonomous, yet supported manner. This, as the findings have suggested, is what doctors value and perceive as important. Finally, we would encourage junior doctor involvement in rota design and planning which may increase their perceived autonomy and therefore buy-in of working practices.

\section{Future research}

Future research is encouraged in two areas. First, to conduct longitudinal research with junior doctors as they progress into specialty training. Second, to conduct similar qualitative research with future junior doctor cohorts working under the average 48 hour limit.

\section{Acknowledgements}

We thank all junior doctors who participated in the study.

\section{Competing Interests}

None declared

\section{Funding}

The author(s) received no financial support for the research, authorship, and/or publication of this article. 


\section{References}

Ahmed-Little, Y., \& Bluck, M. (2006). The European Working Time Directive 2009. British Journal of Healthcare Management, 12, pp. 373-422.

Bamford, N., \& Bamford, D. (2008). The effect of a full shift system on doctors. Journal of Health Organization and Management, 22, pp. 223-237.

Black, P. (2006). The European working time directive. The British Journal of Ophthalmology, 90, pp. 1082-1083.

British Medical Association. (2004). Time's Up 1 August 2004: A guide on the EWTD for junior doctors. London. BMA publications.

British Medical Association. (2008). BMA Survey of members’ views on European Working Time Directive.

<http://www.bma.org.uk/ap.nsf/Content/SummarysurveysEWTD?OpenDocument\&Highlight =2,ewtd $>$ (Retrieved September 2012).

Cairns, H., Hendry, B., Leather, A., \& Moxham, J. (2008). Outcomes of the European Working Time Directive: From 56 to 48 hours is a step too far. British Medical Journal, 337, (a942), pp. 421-422 j.

Cass, H., Smith, I., Unthank, C., Starling, C., \& Collins, J. (2003). Improving compliance with requirements on junior doctors’ hours. British Medical Journal, 327, pp. 270-273. 
Chesser, S., Bowman, K., \& Phillips, H. (2002). The European Working Time Directive and the training of surgeons. British Medical Journal, 325, S69.

Department of Health. (2002). Guidance on working patterns for Junior Doctors. London: Department of Health Publications.

Department of Health. (2004). Extending Independent Nurse Prescribing Within the NHS in England. A Guide for Implementation (Second ed.). London: Department of Health Publications.

Department of Health (2005). The Implementation and Impact of Hospital at Night Pilot Projects. An Evaluation Report. London: Stationary Office.

Duncan, M. (2011). The impact of the Working Time Directive on junior doctors’ working lives. Ph.D Thesis. Loughborough University: UK.

Fernandez, E., \& Williams, D. (2009). Training and the European Working Time Directive: a 7 year review of paediatric anaesthetic trainee caseload data. British Journal of Anaesthesia, 103, pp. 566-569.

Hackman, J., \& Oldham, G. (2010). Not what it was and not what it will be: The future of job design research. Journal of Organizational Behavior, 31, pp. 463-479. 
Humphrey, S., Nahrgang, J., \& Morgeson, F. (2007). Integrating Motivational, Social, and Contextual Work Design Features: A Meta-Analytic Summary and Theoretical Extension of the Work Design Literature. Journal of Applied Psychology, 92, pp. 1332-1356.

Kendall, D., Ahmed-Little, Y., Cousins, D., Sunderland, H., Johnston, M., \& Najim, O. (2009). Achieving the 48-hour week for junior doctors. British Journal of Healthcare Management, 15, pp. 127-131.

King, N. (1998). Template analysis. In: Symon, G., Cassell, C. (Eds.), Qualitative methods and analysis in organizational research: A practical guide, pp. 118-134. Sage, London.

Lowenstein, J. (2003). Where have all the giants gone? Reconciling medical education and the traditions of patient care with limitations on resident work hours. Perspectives in Biology and Medicine, 46, pp. 273-282.

Lowry, J., \& Cripps, J. (2005). Results of the online EWTD trainee survey. Bulletin of the Royal College of Surgeons of England, 87, pp. 86-87.

Mather, H., \& Pounder, R. (2005). Coping with the problems in acute medicine in the postWTD era- A Survey of RCP College Tutors in December 2004. London: Royal College of Physicians.

McDonald, R., \& Eccles, S. (2004). The hospital at night. British Medical Journal Career Focus, 328, 19. 
Moonesinghe, S., Lowery, J., Shahi, N., Millen, A., \& Beard, J. (2011). Impact of reduction in working hours for doctors in training on postgraduate medical education and patients’ outcomes: systematic review. British Medical Journal, 342, pp. d1580.

Landeshauptstadt Kiel v Dr Medical Norbert Jaeger. European Court of Justice, Case C151/02 2002.

Office of Public Sector Information. (1998). The Working Time Regulations < http://www.opsi.gov.uk/si/si1998/19981833.htm> (Retrieved August 2013)

Richards, T. (2009). Running out of time. British Medical Journal, 338, b1507.

Shah, P., Raman, S., \& Vaughan-Williams, E. (2004). European Working Time Directive - a turning stone on the career of junior doctors. Colorectal Disease: The official journal of the Association of Coloproctology of Great Britain and Ireland, 6, pp. 12.

Sindicato de Médicos de Asistencia Pública (SIMAP) v Conselleria de Sanidad y Consumo de la Generalidad Valenciana. Judgement of 3 October 2000. Case C-303/98 European Court Reports 2000:1-7963.

Sturges, J., \& Hanrahan, K. (2004). Comparing telephone and face-to-face qualitative interviewing: a research note. Qualitative Research, 4, pp. 107-117.

Wilkinson, C. (2008). Junior doctors' working hours: Perspective on the reforms. International Journal of Nursing Practice, 14, pp. 200-214. 